Article

\title{
A Torque Impulse Balance Control for Multi-Tooth Fault Tolerant Switched-Flux Machines under Open-Circuit Fault
}

\author{
Yu Wang ${ }^{1, *}$ (1) and Wenjuan Hao ${ }^{1,2}$ (1) \\ 1 Department of Electrical Engineering, Nanjing University of Aeronautics and Astronautics, \\ Nanjing 211116, China; wanghaohao@nuaa.edu.cn \\ 2 College of Jincheng, Nanjing University of Aeronautics and Astronautics, Nanjing 211156, China; \\ hwj@nuaa.edu.cn \\ * Correspondence: wanghaohao@nuaa.edu.cn; Tel.: +86-151-0516-6171
}

Received: 18 June 2018; Accepted: 16 July 2018; Published: 23 July 2018

\begin{abstract}
The multi-tooth fault tolerant switched-flux machines (MTFTSFM) providing both excellent fault tolerant capability and relatively high torque density are good choices for high reliability applications. A rapid control of the electromagnetic torque under open-circuit fault can always be achieved by the direct torque control with voltage vector reconstruction (RDTC); however, with respect to the rotor speed, its dynamic performance is still impacted by the proportion-integration (PI) parameters. Therefore, a torque impulse balance control (TIBC) is investigated in this paper for the MTFTSFM under open-circuit fault to obtain excellent dynamic performance of the rotor speed. During the dynamic state, the electromagnetic torque and the speed can converge at the same time after only one adjustment of the speed by using the optimized voltage vector sequence based on torque impulse balance, thus, achieving the best possible dynamic process for the speed. The TIBC method is carried out on an MTFTSPM machine system, and the correctness and effectiveness are verified.
\end{abstract}

Keywords: switched-flux machine; fault tolerant; torque impulse balance control

\section{Introduction}

Nowadays, multi-electric aircraft (MEA) technology has become a hot topic in the field of aviation. As an important system of the MEA, the electric drive system for electro-mechanical actuators (EMA) should offer the following characteristics [1,2]:

(1) Excellent torque capability and high power density.

(2) High reliability and strong fault tolerant capability.

(3) Superior steady-state and dynamic performance for the system under both healthy condition and open-circuit faults.

As a robust machine, the switched reluctance machine (SRM) exhibits a double salient structure of both stator and rotor, and the concentrated windings are housed on the stator whereas the rotor is passive [3]. Moreover, the SRM is characterized by strong magnetic independence of the phases and by inverter circuit independence during the current control of individual phases. This feature assures an ability of continuing the electromagnetic torque generation also with less number of phases $[4,5]$.

However, when it comes to noise, torque density, and efficiency, the permanent-magnet (PM) machine has more positive features [6]. The introduction of conventional fault tolerant rotor-PM (FTRPM) machines has been widely reported in the literature [7-10], as seen in Figure 1a.

The flux switching permanent magnet (FSPM) machine exhibits the following merits [11]: 
(1) The PMs are mounted on the stator, being free from centrifugal force.

(2) Simple and robust rotor.

(3) The PM field and the armature field distribute in parallel, leading to very low risk of demagnetization.

(4) The FSPM machine can suppress the short-circuit current by increasing self-inductance, whereas the rotor-PM machine needs to increase the leakage inductance to suppress the short-circuit current. Therefore, the SFPM machine can guarantee relatively high torque density while enhancing the ability to suppress the short-circuit [12].

Hence, many fault-tolerant flux-switching PM machines have been proposed. Based on a 12-stator pole, 10-rotor pole, all-pole wound FSPM machine, paper [13] has proposed alternate pole-wound FSPM design, as seen in Figure 1b. Although the 12-stator pole, 14-rotor pole alternate pole-wound fault-tolerant FSPM (FTFSPM) machine using a smaller magnet volume has a little reduction in torque density, it shows relatively lower mutual inductance which will lead to good physically and magnetically isolated capability between phases.

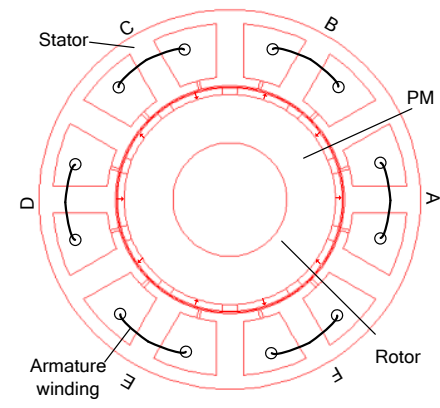

(a)

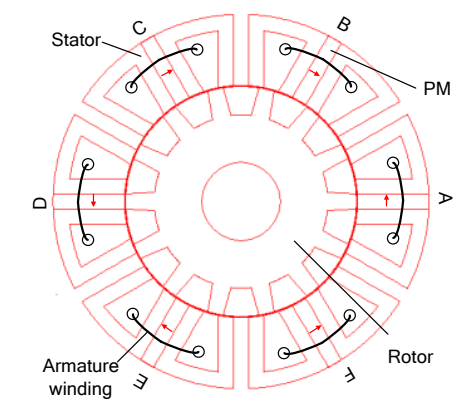

(b)

Figure 1. Fault tolerant PM machines. (a) Fault tolerant rotor-PM(FTRPM) machine; (b) Fault-tolerant FSPM (FTFSPM) machine.

In order to further improve the capability to restrain short-circuit currents, on the basis of the multi-tooth structure [14,15], a multi-tooth 6-stator pole, 19-rotor pole fault-tolerant FSPM (MTFTFSPM) machine is developed with magnetic and physical isolation capability by introducing a decoupling tooth, as shown in Figure 2.

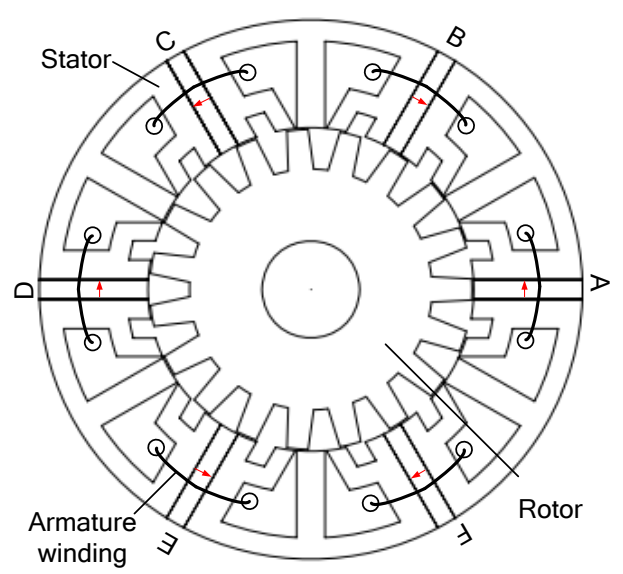

Figure 2. Fault-tolerant FSPM (MTFTFSPM) machine.

In conclusion, both the SRM and the FTFSPM machine exhibit excellent dynamic performance; however, there are several differences: 
(1) The mutual inductance of the SRM is basically zero, whereas the FTFSPM needs the alternate pole-wound structure to reduce the mutual inductance.

(2) The short-circuit current of the SRM is basically zero due to the absence of PMs, whereas the FTFSPM needs a special design to suppress the short-circuit current.

(3) The SRM operates in half-cycle mode, whereas the FTFSPM operates in whole-cycle mode owing to the PMs, making a relatively high torque density and efficiency. In addition, although with doubly salient structure and concentrated winding, the SFPM machine can provide high sinusoidal PM back-electromotive force (back-EMF) due to the complementary winding structure; thus, this kind of machine is suitable for operation in BLAC mode [11,12].

Under phase failure condition, one of the important fault tolerance capabilities of the electric drive system is to guarantee good control performance of both the speed and the torque $[16,17]$.

Paper [3] has given a detailed and in-deep review of the existing fault-tolerant control strategies for SRM. In many applications, the torque ripple is an important issue for the SRM under open-circuit condition, and many techniques were proposed to suppress it [18-24].

Based on one method, the direct instantaneous torque controller, maintaining the torque within an imposed hysteresis band, is applied [25]. However, the currents in this method are uncontrollable, causing the currents in healthy remaining phases to increase under faulty conditions.

In another method, the torque sharing functions (TSFs) are applied. On the basis of the torque and rotor position look-up table, $I=f(T, \theta)$, where $T$ is the torque, $\theta$ is the rotor position, the torque references of each phase are independently changed into imposed currents. Practically, the outputs from the TSF are curves of imposed torques with linear or conventional cosine TSF profiles [26,27]. These outputs are also inputs of the $I=f(T, \theta)$ table, which is converted from the measured $T=f(\theta, I)$ table without taking into account the current rising and falling ability of the SRM. This can have an undesirable effect on the torque ripple (due to torque drops or excesses) when the current controller is not able to reach the demanded current.

In addition, the current profiling method can also reduce the torque ripple, and this method directly employs the three currents from the $I=f(T, \theta)$ table, which are computed in accordance with the current rising and falling ability (and also with respect to minimize torque ripple, or another imposed condition) for healthy and faulty states. This method can reach a minimal torque ripple which is limited just by the switching frequency [28]. In paper [3], the basic approach of current profiling [29-31] has been implemented, and a new methodology of current profile calculation in offline mode for torque ripple minimization was proposed. Based on the two steps that implemented in this strategy, the problem of torque excess (or drop) is eliminated.

In paper [32], the vector control method is applied for the three-phase SFPM machine under an open-circuit condition. By setting the $q$-axis component of armature current invariant before and after the fault, the output torque can be kept constant while offering good steady-state performance of electromagnetic torque under the open-circuit condition. For a six-phase SFPM machine, a fault tolerant control method is presented in [33] to supplement the average torque and offset the harmonic torque under the open-circuit fault by setting $\sqrt{3}$ times the current amplitudes in two of the five remaining healthy coils. In order to reduce the torque ripple during the loss of one phase and reduce the capability requirements of power converter, paper [34] has investigated a compensating method by injecting second-harmonic currents. The main idea of the above methods is to adjust the magnitude and phase angle of the currents in the healthy windings, which is similar to the methods of increasing the value and conducting period of currents in the healthy remaining phases in the SRM system.

In the above vector control methods with current vector compensation (CVC) technology, the dynamic performance of the electromagnetic torque is to some extent limited by the current loop $[35,36]$. Therefore, the direct torque control (DTC) method with fault tolerant capability has been proposed for the alternating current (AC) machines under open-circuit fault. The space vector reconstruction method is used in [37] under the open-circuit condition. This method makes a new area division of the stator flux linkage vector and gives a new switch table, and is found to improve the 
control capability of the electromagnetic torque under the open-circuit condition. Similar to the direct instantaneous torque controller in SRM system, the direct torque control (DTC) method can achieve good dynamic performance of phase currents.

Compared with CVC, the above direct torque control with voltage vector reconstruction technique (RDTC) offers the electromagnetic torque with good dynamic performance. But the dynamic performance of the rotor speed is always affected by the PI parameters of the speed loop.

Thus, to boost the dynamic performance of the rotor speed under open-circuit fault, a torque impulse balance control (TIBC) is investigated in this paper. When the load changes suddenly under open-circuit fault, the RDTC with TIBC (TIBC-RDTC) can calculate an optimal voltage vector sequence which results in the speed with no overshoot and the shortest settling time.

Thus, to boost the dynamic performance of the rotor speed under open-circuit fault, a torque impulse balance control (TIBC) is investigated in this paper. When the load changes suddenly under open-circuit fault, the RDTC with TIB (TIBC-RDTC) can calculate an optimal voltage vector sequence which results in the speed with no overshoot and the shortest settling time.

This paper is organized as follows. The machine topology and torque impulse balance control are introduced in Section 2. The experimental results are presented in Section 3. Finally, conclusions are given in Section 4.

\section{System Structure and Operation Principle}

\subsection{Machine Topology}

Figure 3 shows the armature field distribution of the fault-tolerant PM machines. It can be found that the armature field and the PM field of the FTRPM machine are distributed in series while those of the FTFSPM machine are distributed in parallel. Therefore, armature winding leakage of the FTRPM machine must be increased to restrain short-circuit currents and avoid the demagnetization; however, this will reduce the effectiveness of the armature current and the torque density.

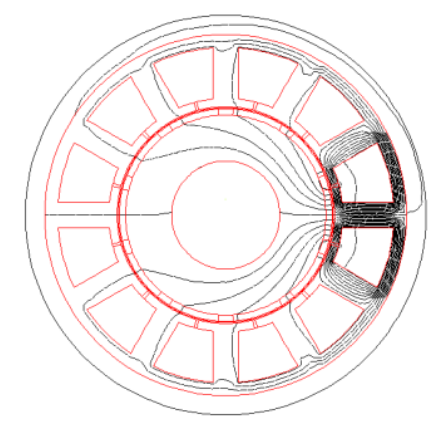

(a)

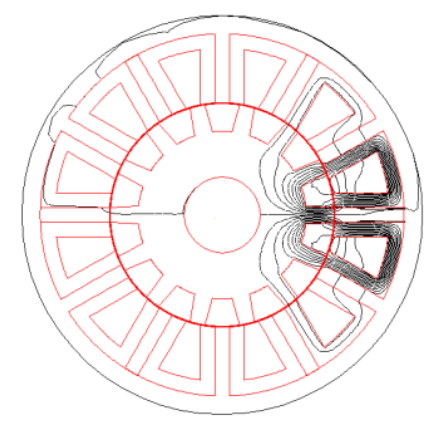

(b)

Figure 3. Armature field distribution: (a) FTRPM machine; (b) FTFSPM machine.

The MTFTFSPM can also obtain 1-per unit (1-p.u.) phase inductance to restrain the short-circuit current without increasing the armature winding leakage. However, when the MTFTFSPM operates under multi-phase (six-phase) condition, the flux-linkage and back-EMF will be asymmetrical $[14,15]$. Although the rotor skewing method can reduce this asymmetry, it will decrease the back-EMF magnitude and the torque density.

Hence, in order to obtain a symmetrical back-EMF without the magnitude reduction, a multi-tooth 6-stator pole, 19-rotor pole fault-tolerant FSPM machine with twisted-rotor (MTFTFSPM-TR) is investigated [12], as shown in Figure 4. As can be seen:

(1) The stagger degree between the two parts of the rotor is $180^{\circ}$ (electrical degree).

(2) The two-part PMs in a stator tooth have opposite magnetization direction. 


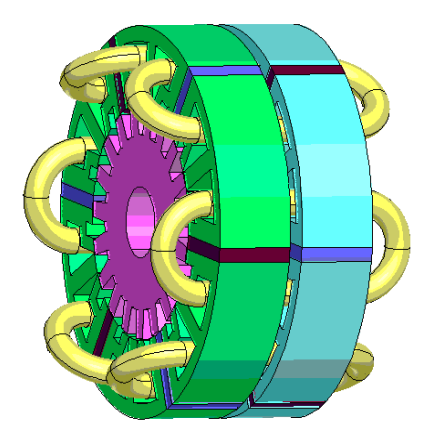

(a)

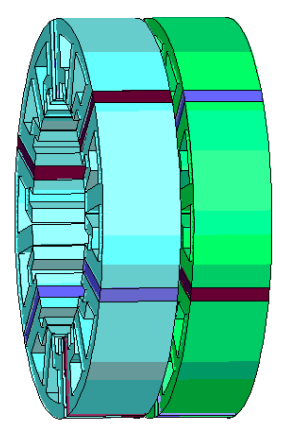

(b)

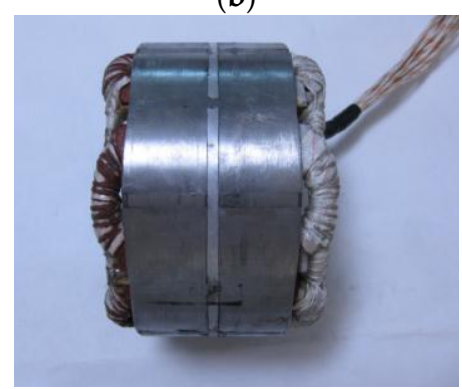

(c)

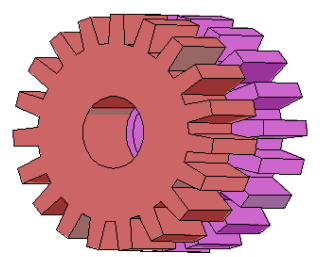

(d)

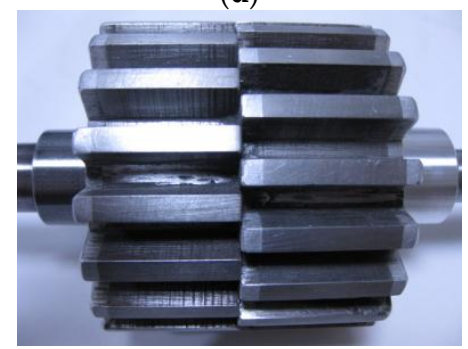

(e)

Figure 4. MTFTSFM: (a) The machine structure; (b) The stator structure; (c) Prototype stator; (d) The rotor structure; (e) Prototype rotor.

Based on the above two features, the back-EMF in each is symmetrical without magnitude reduction (the back-EMF superposition factor of the two parts in each coil is $-\cos 180^{\circ}=1$ ).

In conclusion, the advantages of this topology are as follows [12]: 
(1) The multi-tooth structure can effectively improve the ability to restrain short-circuit currents and maintain a relatively high torque density.

(2) Based on the twisted-rotor, the phase back-EMF of high sinusoidal and symmetric can be obtained without amplitude decrease.

\subsection{Influence of PI Controller on Rotor Speed Dynamic Performance}

The diagram of the direct torque control is given in Figure 5.

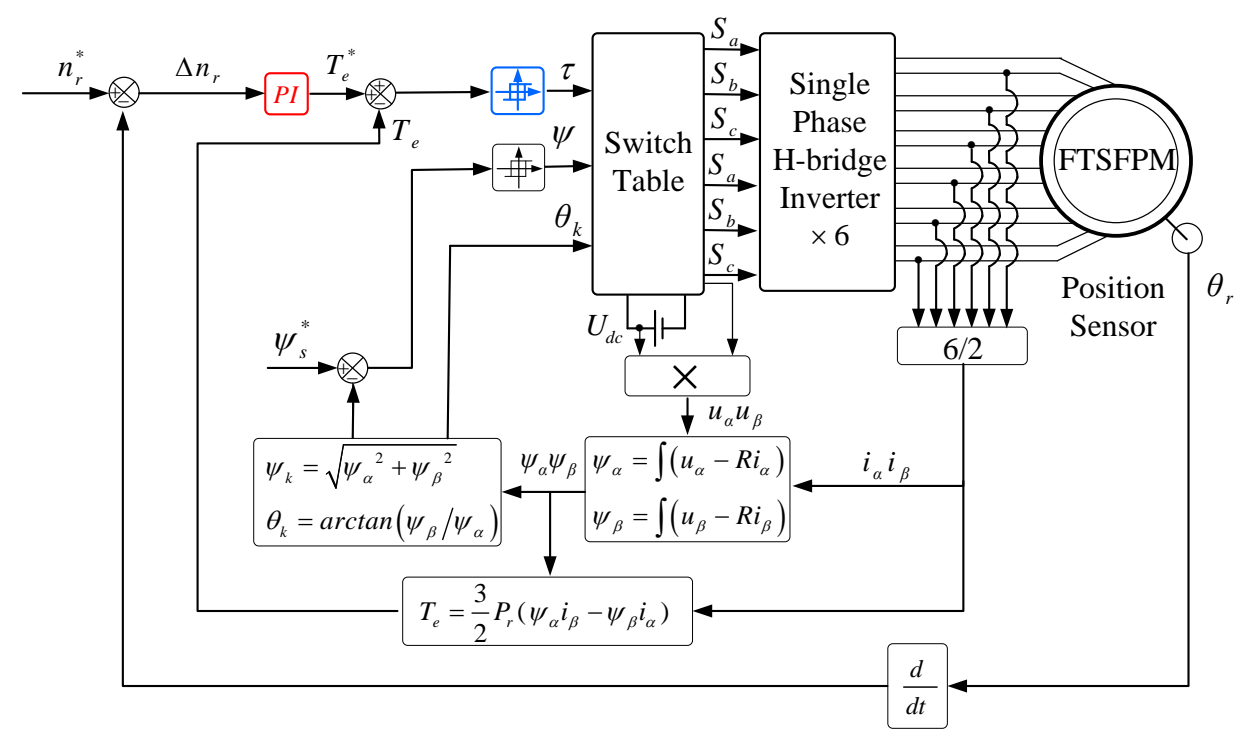

Figure 5. Diagram of the direct torque control.

The voltage vectors and switch table under healthy condition are given in Figure 6 and Table 1, respectively. Under open-circuit fault, the voltage vectors and switch table should be reconstructed, as seen in Figure 7 and Table 2, respectively.

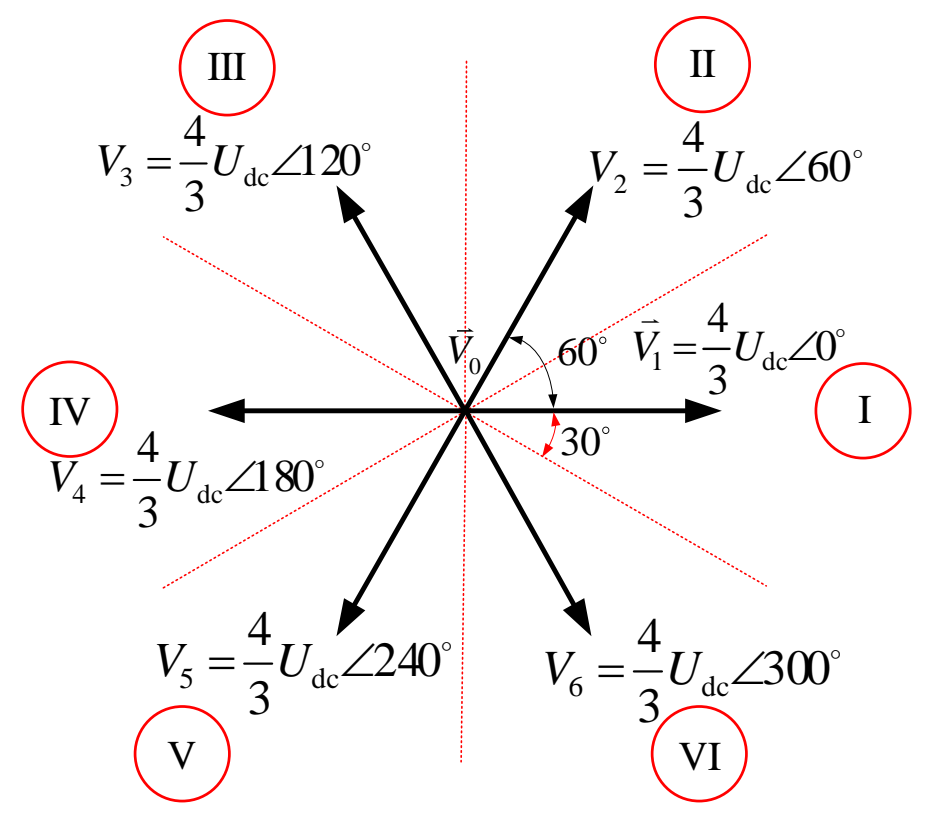

Figure 6. Voltage vectors. 
Table 1. Switch table.

\begin{tabular}{ccccccc}
\hline Torque and Flux-Linkage & I & II & III & IV & V & VI \\
\hline$T_{e} \uparrow \psi_{s} \uparrow$ & $V_{2}$ & $V_{3}$ & $V_{4}$ & $V_{5}$ & $V_{6}$ & $V_{1}$ \\
$T_{e} \uparrow \psi_{s} \downarrow$ & $V_{3}$ & $V_{4}$ & $V_{5}$ & $V_{6}$ & $V_{1}$ & $V_{2}$ \\
$T_{e} \downarrow \psi_{s} \uparrow$ & $V_{0}$ & $V_{0}$ & $V_{0}$ & $V_{0}$ & $V_{0}$ & $V_{0}$ \\
$T_{e} \downarrow \psi_{s} \downarrow$ & $V_{0}$ & $V_{0}$ & $V_{0}$ & $V_{0}$ & $V_{0}$ & $V_{0}$ \\
\hline
\end{tabular}

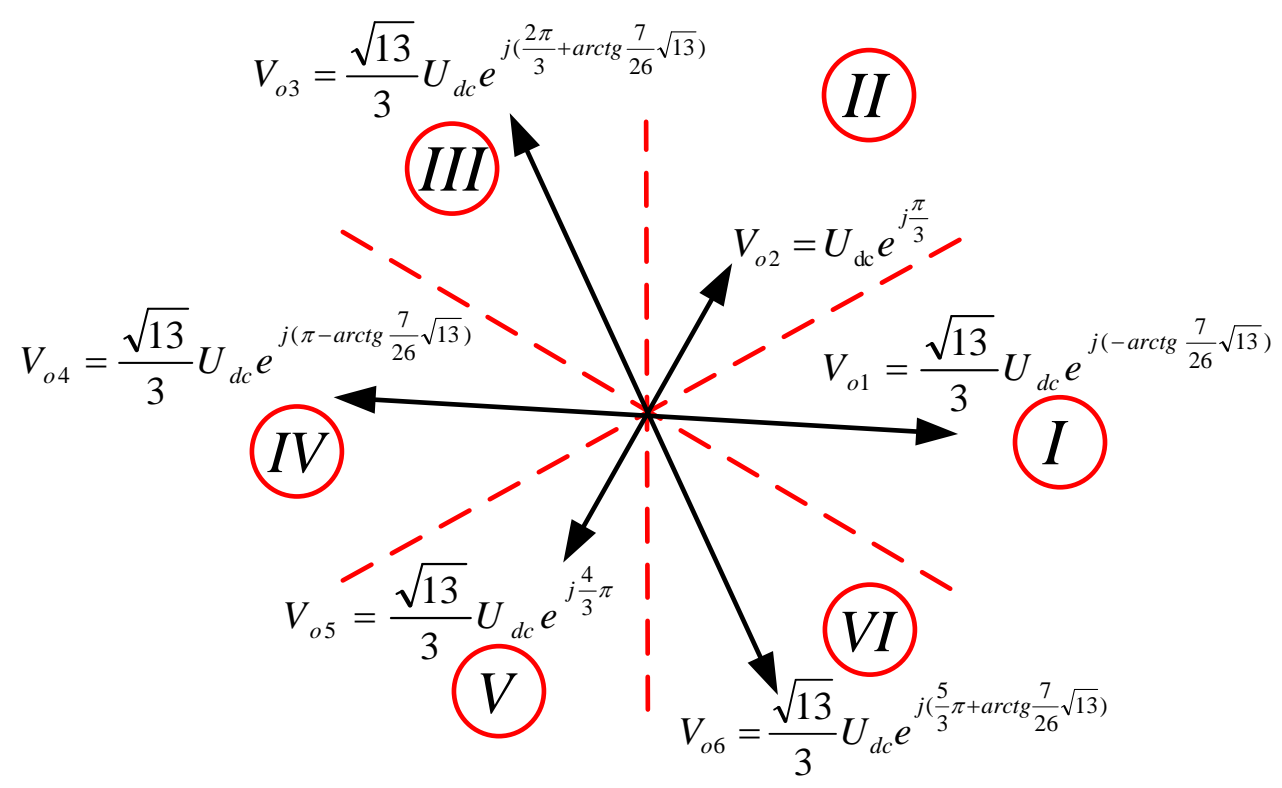

Figure 7. Reconstructed voltage vectors under phase B open-circuit fault.

Table 2. Switch table when phase B in open-circuit fault.

\begin{tabular}{ccccccc}
\hline Torque and Flux-Linkage & I & II & III & IV & V & VI \\
\hline$T_{e} \uparrow \psi_{s} \uparrow$ & $V_{o 2}$ & $V_{o 3}$ & $V_{o 4}$ & $V_{o 5}$ & $V_{o 6}$ & $V_{o 1}$ \\
$T_{e} \uparrow \psi_{s} \downarrow$ & $V_{o 3}$ & $V_{o 4}$ & $V_{o 5}$ & $V_{o 6}$ & $V_{o 1}$ & $V_{o 2}$ \\
$T_{e} \downarrow \psi_{s} \uparrow$ & $V_{o 6}$ & $V_{o 1}$ & $V_{o 2}$ & $V_{o 3}$ & $V_{o 4}$ & $V_{o 5}$ \\
$T_{e} \downarrow \psi_{s} \downarrow$ & $V_{o 5}$ & $V_{o 6}$ & $V_{o 1}$ & $V_{o 2}$ & $V_{o 3}$ & $V_{o 4}$ \\
\hline
\end{tabular}

The direct torque control with voltage vector reconstruction (RDTC) can effectively reduce the open-circuit fault torque ripple; thus, the steady-state performance of the system is improved, but the dynamic performance of the rotor speed is affected by the PI parameters of the speed loop.

The dynamic process under a sudden load change for the DTC is shown in Figure 8. At $t_{2}, t_{4}, t_{6}, t_{8}$, $t_{10}$ and $t_{12}, n_{r}=n_{r}^{*}$ because $T_{e} \neq T_{l}, n_{r}$ will continue to change. At $t_{1}, t_{3}, t_{5}, t_{7}, t_{9}$ and $t_{13}$, the change rate of the speed is zero because $T_{e}=T_{l}$, and the change of $T_{e}$ will continue with $T_{e}^{*}$, because $n_{r} \neq n_{r}^{*}$.

As can be seen from Figure 8, after a certain adjustment process and adjustment time, the speed is finally converged through a proper group of PI parameters. However, the dynamic process of the speed cannot be guaranteed to be optimal. The speed dynamic responses, including settling time, peak value time, speed dip, overshoot amount and adjustment times, will be different if PI parameters of the speed loop are different. 


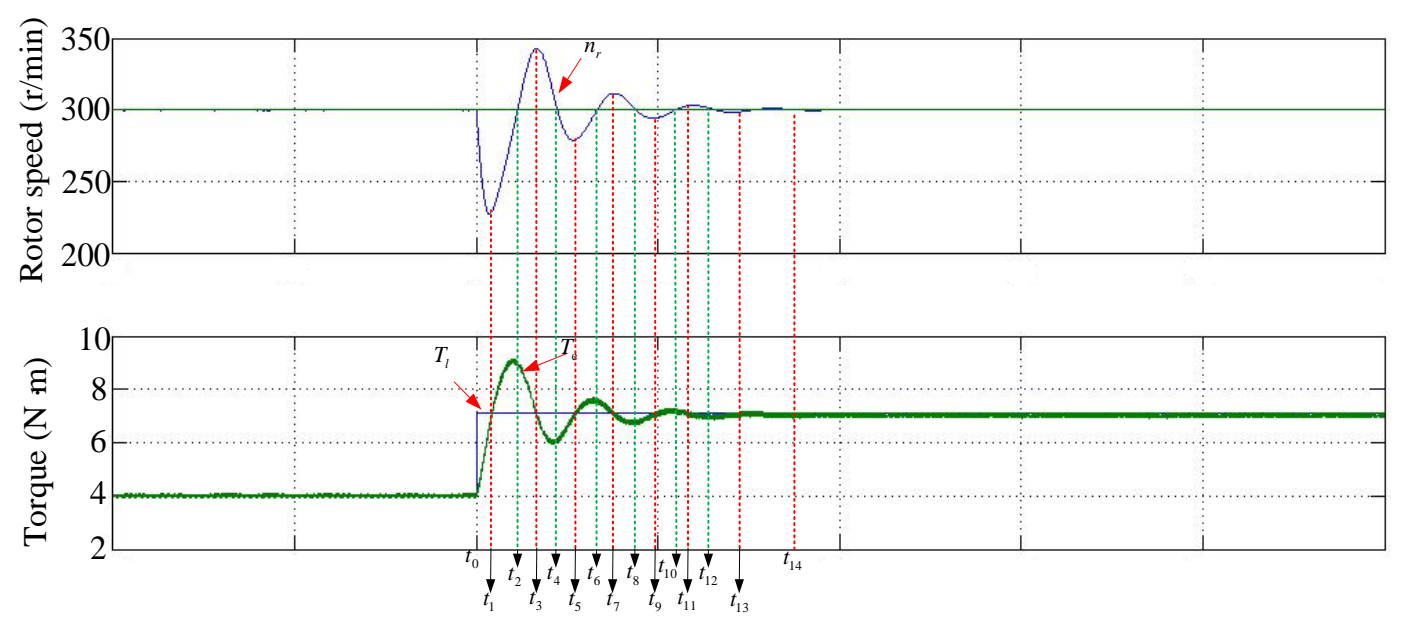

Time $(500 \mathrm{~ms} / \mathrm{div})$

Figure 8. The dynamic process under a sudden load sudden for the direct torque control (DTC).

Some key conclusions are found based on above analysis, as follows:

(1) For the control system, the electromagnetic torque and the rotor speed converge at the same time are sufficient conditions for restoring to the steady-state.

(2) The PI parameters of the speed loop in the RDTC always affect the dynamic response of both electromagnetic torque and rotor speed. The PI controller cannot possibly guarantee the optimal dynamic performance.

(3) A group of switching vector sequences can be found to simultaneously restore the electromagnetic torque and the rotor speed at $t_{1}$. Thus, the speed can be restored to the reference after a decrease and increase only once without overshooting, that is, the possible optimal dynamic response of $n_{r}$ can be obtained.

\subsection{Torque Impulse Balance Control}

Figure 9 shows the synchronous buck converter, where $V_{\text {in }}$ is the input voltage, $V_{o}$ is the output voltage, $V_{c}$ is the capacitor voltage, $i_{L}$ is the inductance current, $i_{C}$ is the capacitor current and $i_{o}$ is the output current.

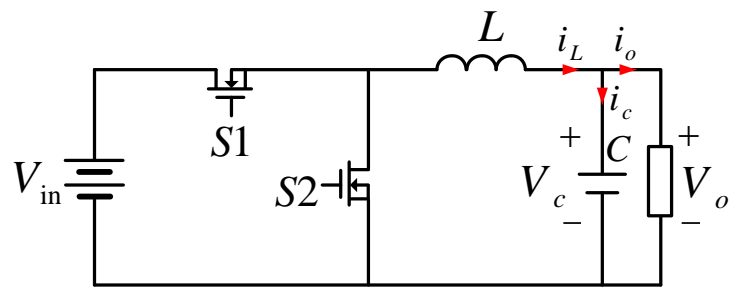

Figure 9. Synchronous buck converter.

For output voltage regulation, the voltage mode control based on PI controller can hardly guarantee the optimal dynamic performance of the output voltage. Generally speaking, the design objectives for voltage mode control, or other conventional linear control methods are to make the steady state error converge to zero and to achieve wide bandwidth with sufficient phase margin. The design is based on frequency domain analysis and does not focus on the time-domain response. Additionally, since the controller is based solely on the small signal response of the converter, it cannot possibly guarantee optimal large signal dynamic performance. Therefore, the charge balance control (CBC) is proposed to achieve the best possible dynamic response [38]. 
The waveforms of buck converter under steady-state are shown in Figure 10, during a sampling time $\left(T_{s}\right)$, can obtain:

$$
V_{c}\left(T_{s}\right)-V_{c}(0)=\frac{1}{C} i_{c a v g}=\frac{1}{C \times T_{s}} \int_{0}^{T_{s}} i_{c}(t) d t=0
$$

Then, extend the principle of (1) to transient period,

$$
V_{c}\left(t_{a}\right)-V_{c}\left(t_{b}\right)=\frac{1}{C} i_{c a v g}=\frac{1}{C \times\left(t_{b}-t_{a}\right)} \int_{t_{a}}^{t_{b}} i_{c}(t) d t=0
$$

It can be observed from (2) that voltage recovers to the original value when the net charge is balanced.

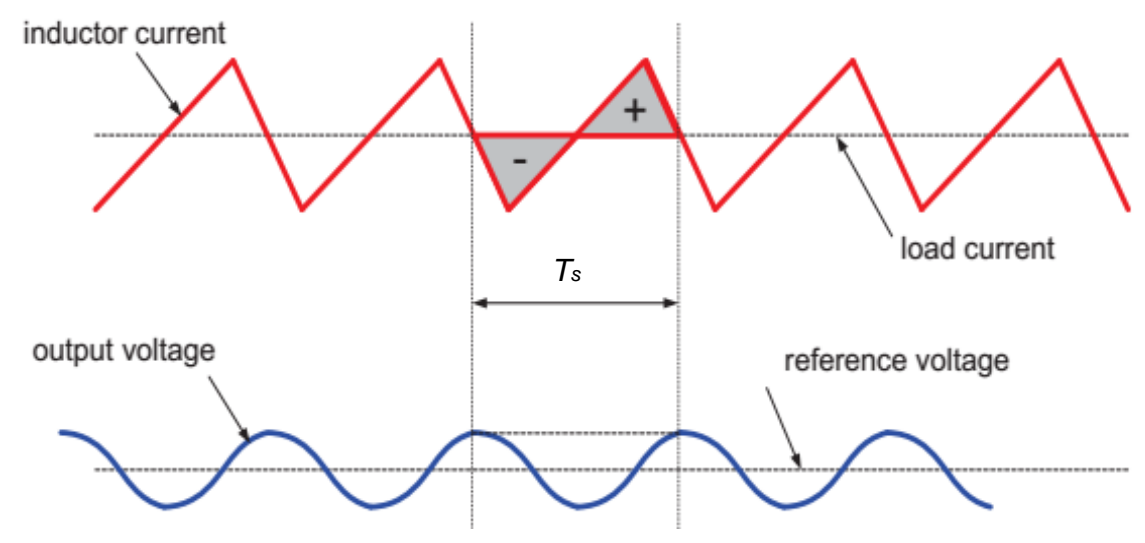

Figure 10. Waveforms of buck converter under steady-state.

According to (2), the optimal inductor current path for load current change can be achieved, as seen in Figure 11. In Figure 11, from $t_{0}$ to $t_{2}$, the inductor current is rising; from $t_{2}$ to $t_{3}$, the inductor current is decreasing, and $A_{\text {charge }}=A_{\text {discharge }}$. In this condition, the shortest recover time is achieved and there is no overshoot in the voltage.

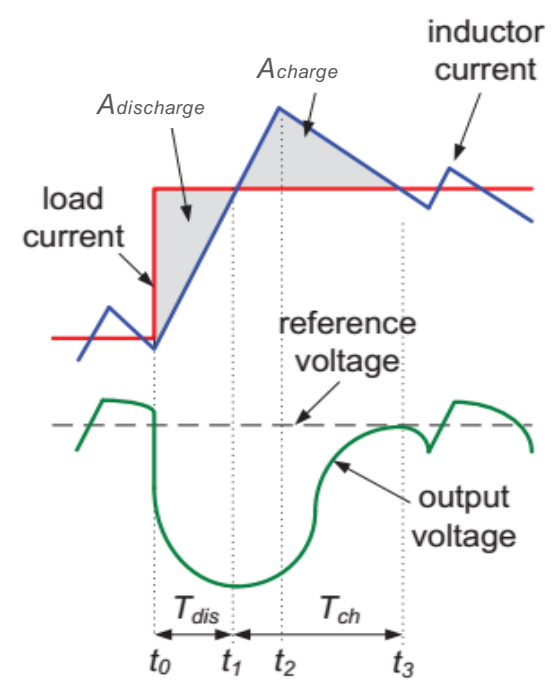

Figure 11. Optimal inductor current path for load current change (top: inductor current, bottom: capacitor voltage). 
The above control approach can be applied to the motor drive system to make the dynamic performance of the speed independent of the PI parameters and the speed converge in the shortest time without overshoot.

The $T-i$ analogy relationships can be found, as shown in Table 3.

Table 3. The $T-i$ analogy relationships.

\begin{tabular}{ccc}
\hline Terms for Comparison & Mechanical System & Electrical System \\
\hline Coordinate & Angular displacement $\theta$ & Flux-linkage $\psi$ \\
Velocity & Angular velocity $\omega$ & Voltage $u$ \\
Force & Torque $T$ & Current $i$ \\
Inertial element & Moment of inertia $J$ & Capacitor $C$ \\
Elastic element & Torsional stiffness coefficient $K_{\theta}$ & Inductance reciprocal $1 / L$ \\
Resistance element & Rotation resistance coefficient $R_{\omega}$ & Conductance $G$ \\
\hline
\end{tabular}

On the basis of above analysis, the variables of the motor mechanical system have analogous relationships with those of the electrical system. Therefore, the torque impulse of the motor mechanical system corresponds to the amount of charge of the electric system; then, the torque impulse balance control of the motor mechanical system based on (10) corresponds to the charging balance control (CBC) of the capacitor based on (9). Similarly, the control target of the torque impulse balance control is to achieve a quick dynamic response.

Take the Buck converter as an example, in the charging balance control, when the switch is on, the voltage of the capacitor is rising; when the switch is off, the voltage of the capacitor is decreasing. In the motor drive system, when the forward vector is applied, the electromagnetic torque is increasing; when the backward vector or the zero vectors is applied, the electromagnetic torque is decreasing. Therefore, applying the forward vector in the motor drive system corresponds to turning the switch on in the converter system, and applying the backward vector or zero vector in the motor drive system corresponds to turning the switch off in the converter system.

According to the above analysis, the torque balance control is investigated.

By neglecting the damping coefficients, the motion equation of the machine is:

$$
T_{e}-T_{l}=J \frac{d \omega}{d t}
$$

Here, $J$ is the moment of inertia, $T_{e}$ is the electromagnetic torque of the machines, $T_{l}$ is the load torque, and the integral form of (3) is

$$
\int_{a}^{b}\left(T_{e}-T_{l}\right) d t=J\left(\omega_{a}-\omega_{b}\right)
$$

It can be found from (4), at moment $a$, and after that, at any moment when $\omega_{a}-\omega_{b}$, the following equation can be obtained:

$$
\int_{a}^{b}\left(T_{e}-T_{l}\right) d t=0
$$

Thus, the load torque impulse is balanced by the electromagnetic torque impulse.

Hence, Figure 12 gives the optimal response to load sudden change for the electromagnetic torque. $T_{l}$ changes suddenly at $t_{0}$; from $t_{0}$ to $t_{2}$, the forward vectors are employed and $T_{e}$ increases continuously. From $t_{2}$ to $t_{3}$, the zero vectors are employed and $T_{e}$ decreases continuously. 


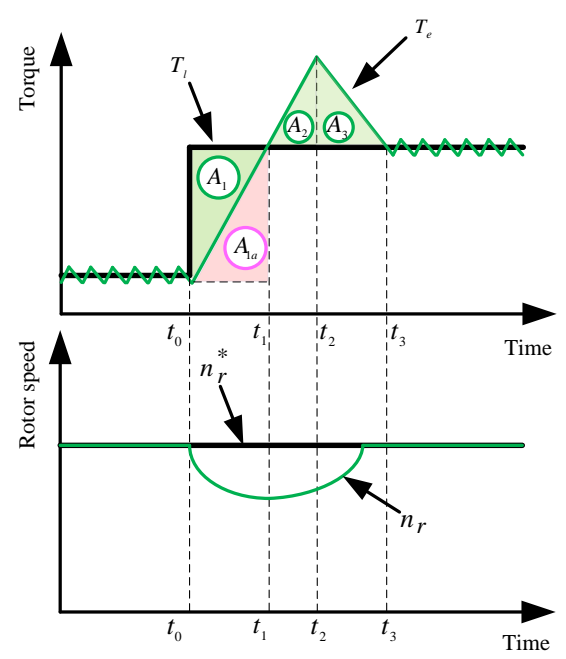

Figure 12. Optimal response to a sudden load sudden for the electromagnetic torque.

Both $T_{e}$ and $n_{r}$ can respectively converge to their corresponding reference values at $t_{3}$, if a proper $t_{2}$ is obtained to satisfy $A_{1}=A_{2}+A_{3}$. Thus, the shortest restoration time of $n_{r}$ and the minimum ripple of the speed are reached.

In Figure 6, $A_{1}=A_{2}+A_{3}$ can be replaced by:

$$
A_{1 \mathrm{a}}=A_{2}+A_{3}
$$

When using the feed forward control, $T_{e H}+T_{S}$ can be obtained as:

$$
T_{e}=\frac{6}{2 L_{q}} P_{r} \psi_{s} \psi_{p m} \sin \theta
$$

Here, $P_{r}$ represents the rotor pole pairs, $L_{q}$ is the inductance of $q$-axis, $\psi_{s}$ is the amplitude of the stator flux linkage, $\psi_{p m}$ is the amplitude of the PM flux linkage, respectively, and $\theta$ is the torque angle.

$T_{e}$ is linearly related to $\sin \theta$ when $\psi_{s}$ is kept constant, thus, Figure 6 is identical to Figure 13. In Figure 13, $\sin \gamma=2 T_{l} L_{q} / 6 P_{r} \psi_{s} \psi_{p m}$.

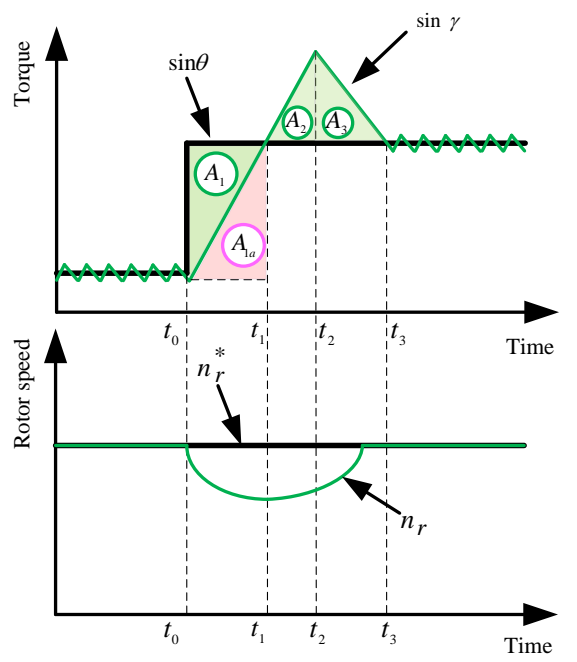

Figure 13. Optimal response to load sudden change for the torque angle.

The curve slope of $\sin \theta$ from $t_{0}$ to $t_{2}$ can be expressed as: 
I. In sector II and V of the stator flux linkage, see (8).

$$
\begin{aligned}
k_{1} & =\frac{\sin \left(\theta_{0}+\omega n T-\omega_{r} n T\right)-\sin \left[\theta_{0}+\omega(n-1) T-\omega_{r}(n-1) T\right]}{T} \\
& =\cos \frac{\left.2 \theta_{0}+\omega(2 n-1) T-\omega_{r}(2 n-1) T\right]}{T}\left(\frac{1}{T} \operatorname{arctg} \frac{2 \sqrt{3} U_{d c} \times T}{\pi \psi_{s}}-\omega_{r}\right)
\end{aligned}
$$

II. In sector I, III, IV and VI of the stator flux linkage, see (9).

$$
\begin{aligned}
k_{1} & =\frac{\sin \left(\theta_{0}+\omega n T-\omega_{r} n T\right)-\sin \left[\theta_{0}+\omega(n-1) T-\omega_{r}(n-1) T\right]}{T} \\
& =\cos \frac{\left.2 \theta_{0}+\omega(2 n-1) T-\omega_{r}(2 n-1) T\right]}{T}\left(\frac{1}{T} \operatorname{arctg} \frac{3 \sqrt{3} U_{d c} \times T}{2 \pi \psi_{s}}-\omega_{r}\right)
\end{aligned}
$$

Here $U_{d c}$ is the converter direct current (DC) link voltage, $\omega$ is the angular frequency of the stator flux linkage vector when the forward vectors are applied to the machine, $\mathrm{T}$ and $n$ are the interrupt period and the number of interrupt periods, respectively, $\omega_{r}$ is the rotor angular frequency, and $\theta_{0}$ is the torque angle at $t_{0}$.

The curve slop of $\sin \theta$ from $t_{2}$ to $t_{3}$ can be expressed as:

I. In sector II and V of the stator flux linkage, see (10).

$$
\begin{aligned}
k_{2} & =\frac{\sin \left(\theta_{0}-\omega n T-\omega_{r} n T\right)-\sin \left[\theta_{0}-\omega(n-1) T-\omega_{r}(n-1) T\right]}{T} \\
& =\cos \frac{\left.2 \theta_{0}-\omega(2 n-1) T-\omega_{r}(2 n-1) T\right]}{T}\left(-\frac{1}{T} \operatorname{arctg} \frac{2 \sqrt{3} U_{d c} \times T}{\pi \psi_{s}}-\omega_{r}\right)
\end{aligned}
$$

II. In sector I, III, IV and VI of the stator flux linkage, see (11).

$$
\begin{aligned}
k_{2} & =\frac{\sin \left(\theta_{0}-\omega n T-\omega_{r} n T\right)-\sin \left[\theta_{0}-\omega(n-1) T-\omega_{r}(n-1) T\right]}{T} \\
& =\cos \frac{\left.2 \theta_{0}-\omega(2 n-1) T-\omega_{r}(2 n-1) T\right]}{T}\left(-\frac{1}{T} \operatorname{arctg} \frac{3 \sqrt{3} U_{d c} \times T}{2 \pi \psi_{s}}-\omega_{r}\right)
\end{aligned}
$$

where $\theta_{2}$ is the torque angle at $t_{2}$.

Then, (6) is derived to

$$
A_{1 a}=A_{2}+\frac{k_{1}}{-k_{2}} A_{2}
$$

On the basis from (1) to (12) we can obtain:

$$
\int_{t_{0}}^{t_{1}} k_{1} t d t=\int_{t_{1}}^{t_{2}} k_{1} t d t+\frac{k_{1}}{-k_{2}} \int_{t_{1}}^{t_{2}} k_{1} t d t=\int_{t_{1}}^{t_{2}}\left(k_{1}-\frac{k_{1}^{2}}{k_{2}}\right) t d t
$$

Then, according to (13), $t_{2}$ can be achieved via the following steps:

(1) First, achieve the double integral value of $k_{1}$ from $t_{0}$ to $t_{1}$, where $t_{1}$ is the moment when $d \omega_{r} / d t=0$.

(2) Then, calculate the double integral value of $\left(k_{1}-k_{1}^{2} / k_{2}\right)$ using $t_{1}$, the moment when this integral value is equal to $\iint_{t_{0}}^{t_{1}} k_{1} d t d t$ is $t_{2}$.

The RDTC system with torque integral balance control (TIBC-RDTC) is shown in Figure 14. 


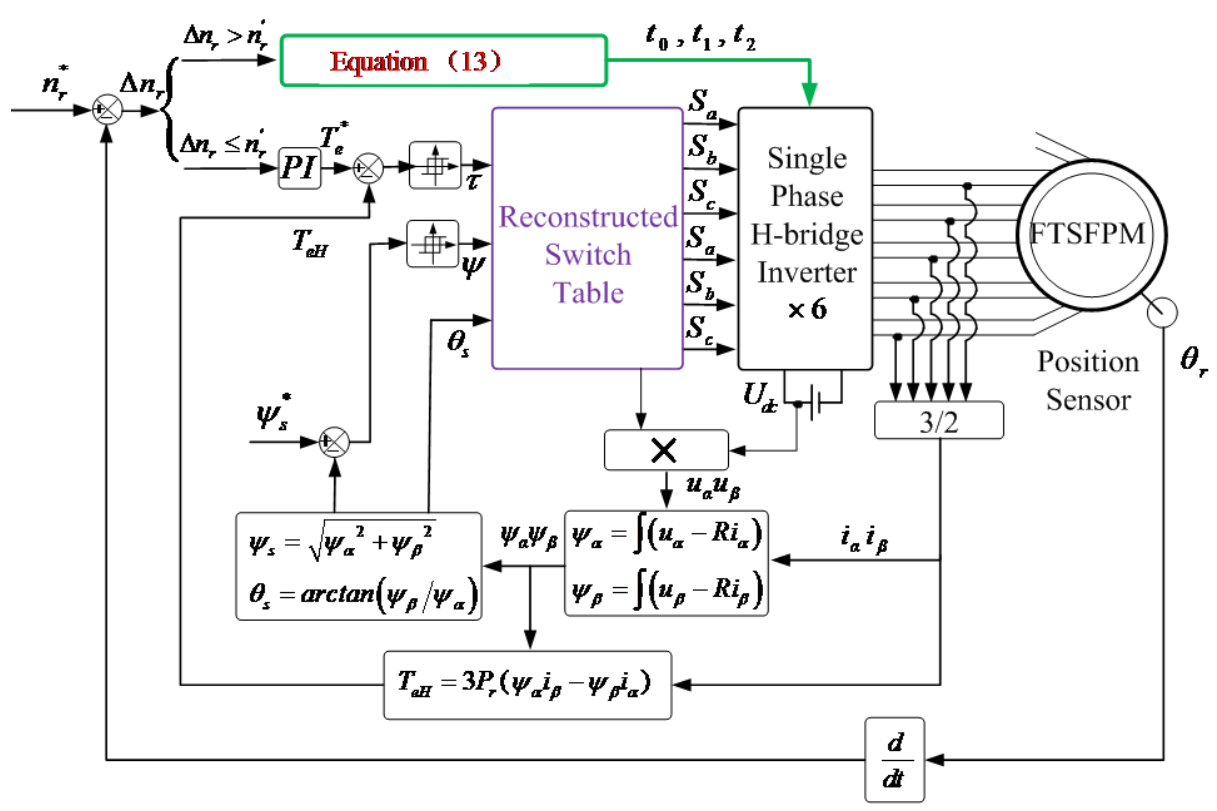

Figure 14. The RDTC system with torque integral balance control (TIBC-RDTC).

\section{Experimental Results}

Figures 15 and 16 show the experimental platform and its diagram, respectively. Figure 16 shows the test bench. The design specifications and parameters of the MTFTFSPM machines are as follows: the stator outer diameter is $150 \mathrm{~mm}$, the stator inner diameter is $89.5 \mathrm{~mm}$, the air-gap is $0.5 \mathrm{~mm}$, the stack length is $60 \mathrm{~mm}$, the stator slot number is 12 , the rotor pole number is 19 , the number of armature turns per coil is 50, the rated armature current is $8.6 \mathrm{~A}$, the magnet remanence is $1.15 \mathrm{~T}$, the magnet relative permeability is 1.05.The rated electro-magnetic torque of the machines is 9.6 Nm. The load of the machine is provided by a magnetic powder brake ZF20B.

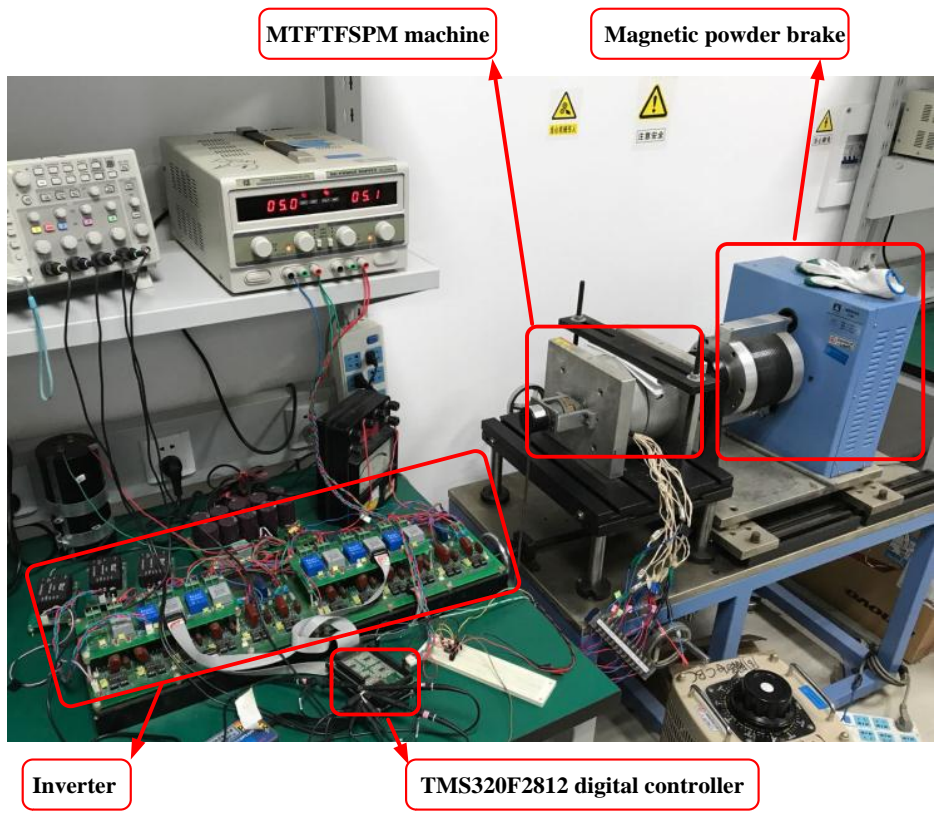

Figure 15. Test bench. 


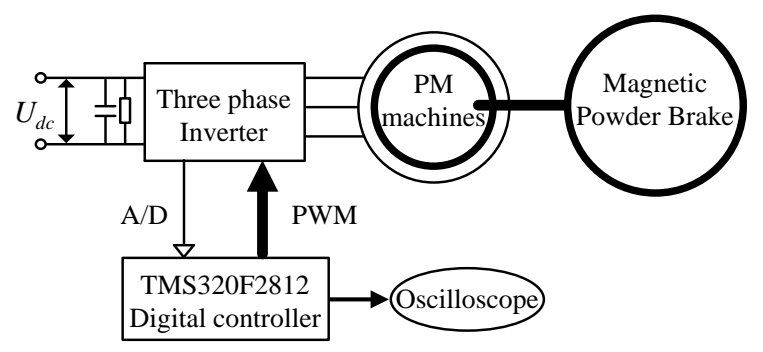

Figure 16. The diagram of test bench.

The phase currents $i_{a}, i_{b}, i_{c}$ are acquired by current sensors LA28-NP (measuring range: 0-25 A) and phase voltages $u_{a}, u_{b}, u_{c}$ are acquired by voltage sensor LA28-P (measuring range: $0-500 \mathrm{~V}$ ). The rotor speed is measured by encoder NOC-SP10000-2MD. The program is developed by a TMS320F2812 digital controller, and the sampling period is $32 \mu \mathrm{s}$.

\subsection{Experimental Results under Open-Circuit Fault}

\subsubsection{Steady-State Performance}

For the MTFTSFPM machine under open-circuit fault, Figures 17 and 18 give the waveforms of $T_{e}$ and $n_{r}$ by using DTC and RDTC, respectively. The torque ripple peak value in Figure 17 is $2.4 \mathrm{~N} \cdot \mathrm{m}$ while that in Figure 18 is only $0.9 \mathrm{~N} \cdot \mathrm{m}$, indicating that the RDTC can effectively suppress the torque ripple.

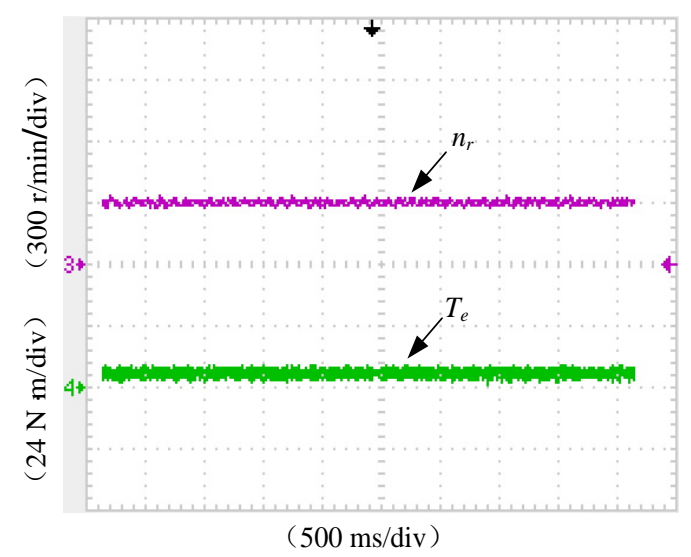

Figure 17. $T_{e}$ and $n_{r}$ of the MTFTSFPM machine under open-circuit fault using DTC.

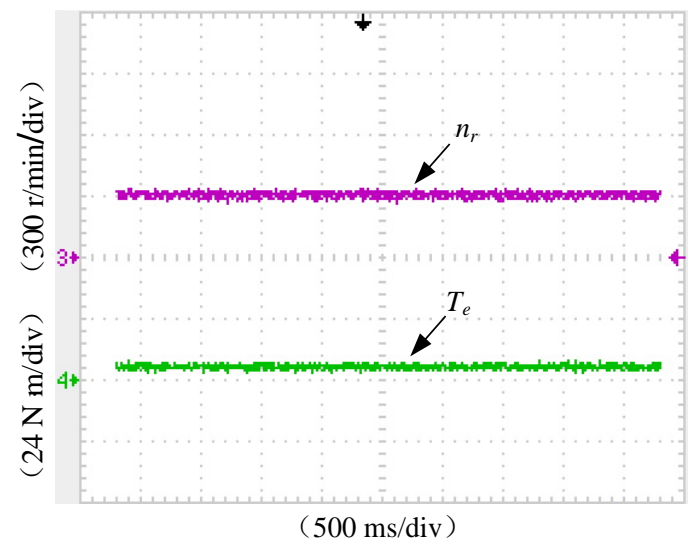

Figure 18. $T_{e}$ and $n_{r}$ of the MTFTSFPM machine under open-circuit fault using RDTC. 


\subsubsection{Dynamic Performance}

For the MTFTSFPM machine under open-circuit fault, Figures 19 and 20 give the dynamic performance of RDTC without TIBC when $P=7.2, I=0.96$ and $P=9.5, I=1.1$, respectively. Figure 21 gives the dynamic performance of TIBC-RDTC.

For RDTC without TIBC, the PI parameters are analyzed and optimized using time domain analysis. The variation of PI parameters affects the pole distribution of the control system closed-loop transfer function, and further affects the speed dynamic performance.

When the poles are near to the imaginary axis, $n_{r}$ has a long period of oscillation before it converges, and the peak value of the oscillation is high, whereas when the poles are far away from the imaginary axis, the adjustment of $n_{r}$ lasts for a long time.

When the poles are at a moderate distance from the imaginary axis, the dynamic performance of $n_{r}$ is improved, as shown in Figure 19.

Furthermore, when the poles are at a moderate distance from both the imaginary axis and the solid axis, the overall performance of $n_{r}$ is excellent, as seen in Figure 20.

In Figure 21, when the TIBC are employed, the settling time is only $50 \mathrm{~ms}$, the speed dip is only $60 \mathrm{r} / \mathrm{min}$ and there is no overshoot. It can be found that, consistent with previous theoretical analysis, the shortest possible convergence time in the dynamic process to load can be obtained and the speed overshoot can be minimized based on the TIBC-RDTC.

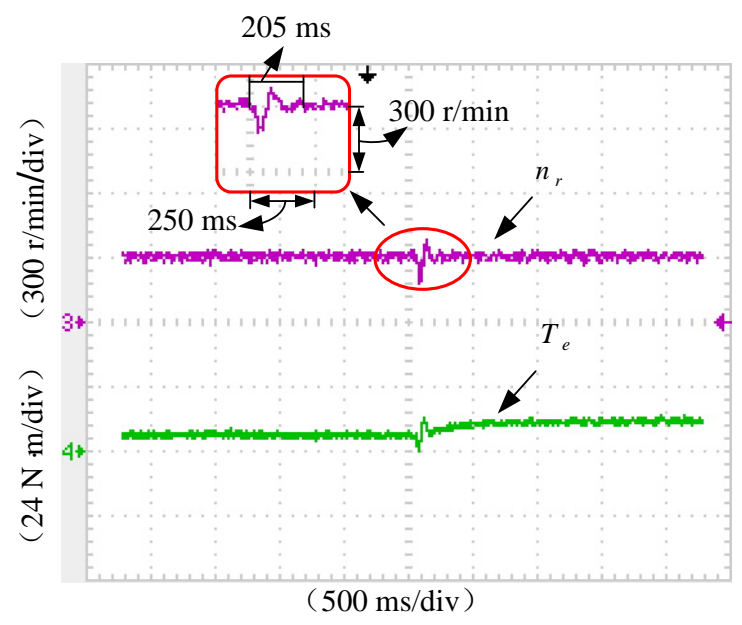

Figure 19. Dynamic performance of RDTC without $\operatorname{TIBC}(P=7.2, I=0.96)$.

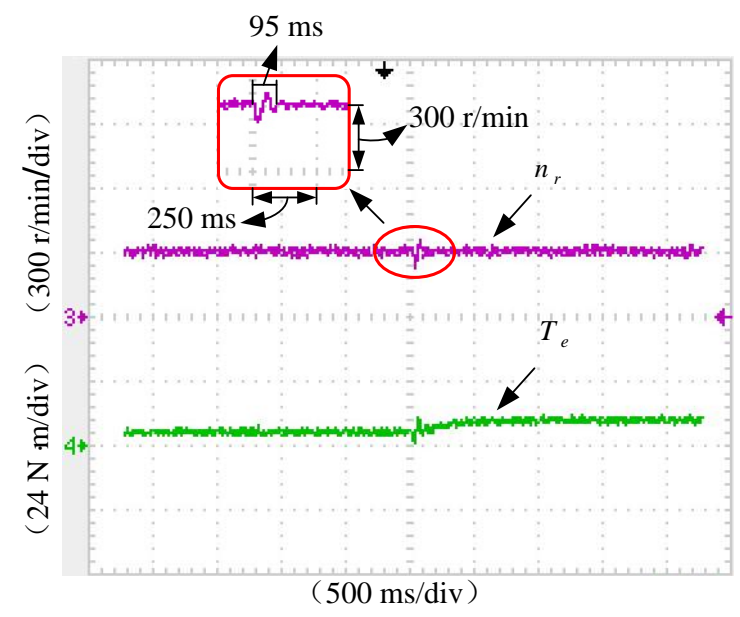

Figure 20. Dynamic performance of RDTC without TIBC $(P=9.5, I=1.1)$. 


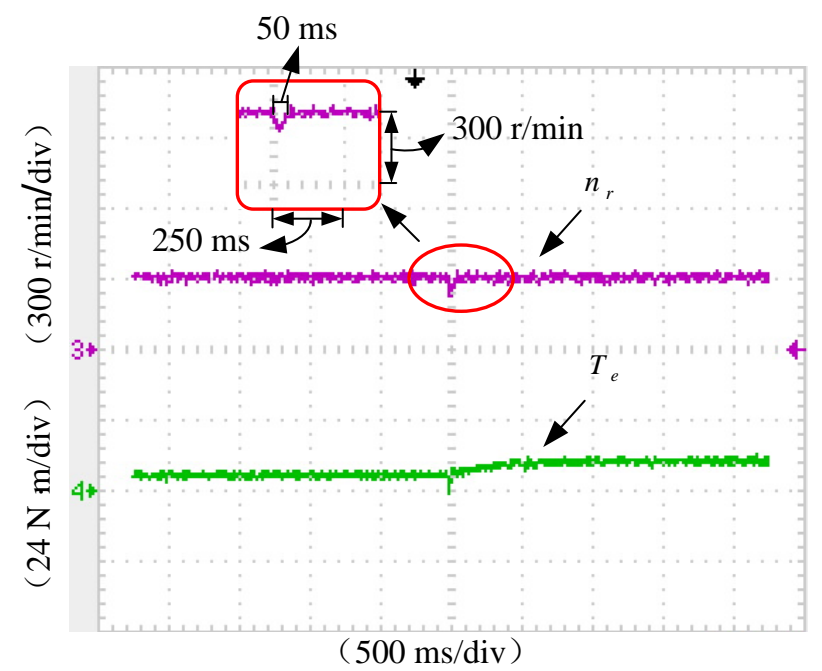

Figure 21. Dynamic performance of RDTC with TIBC (TIBC-RDTC).

For easier comparison, the performance metrics of RDTC without TIBC and with TIBC are given in Table 4.

Table 4. Performance metrics of the direct torque control with voltage vector reconstruction (RDTC) without torque impulse balance control (TIBC) and with TIBC.

\begin{tabular}{|c|c|c|c|c|c|}
\hline Methods & $\begin{array}{c}\text { Settling } \\
\text { Time }\left(t_{\mathrm{s}}\right)\end{array}$ & $\begin{array}{l}\text { Peak Value } \\
\text { Time }\left(t_{p}\right)\end{array}$ & $\begin{array}{l}\text { Speed Dip } \\
\Delta n \text {-down }\end{array}$ & $\begin{array}{c}\text { Over Shoot } \\
\text { Amount }\left(\propto^{\circ} \%\right)\end{array}$ & $\begin{array}{c}\text { Adjustment } \\
\text { Times }(Z)\end{array}$ \\
\hline $\begin{array}{l}\text { RDTC without TIBC } \\
\quad(P=7.2, I=0.96)\end{array}$ & $205 \mathrm{~ms}$ & $75 \mathrm{~ms}$ & $120 \mathrm{r} / \mathrm{min}$ & $16.67 \%$ & 3 \\
\hline $\begin{array}{l}\text { RDTC without TIBC } \\
(P=9.5, I=1.1)\end{array}$ & $95 \mathrm{~ms}$ & $60 \mathrm{~ms}$ & $70 \mathrm{r} / \mathrm{min}$ & $13.33 \%$ & 4 \\
\hline $\begin{array}{l}\text { RDTC with TIBC } \\
\text { (TIBC-RDTC) }\end{array}$ & $50 \mathrm{~ms}$ & $50 \mathrm{~ms}$ & $60 \mathrm{r} / \mathrm{min}$ & $0.00 \%$ & 1 \\
\hline
\end{tabular}

In Table 4, where the definition of the variables are as follows:

Settling time $\left(t_{\mathrm{s}}\right)$ : The minimum time required for the speed response to achieve its final value and keep within $2 \%$ error range of the final value.

Peak value time $\left(t_{p}\right)$ : The time required for the speed response exceeding its final value to reach the first peak.

Speed dip $(\Delta n)$-down: Maximum drop value of speed response.

Overshoot amount $(\sigma \%): \sigma \%=\frac{n\left(t_{p}\right)-n(\infty)}{n(\infty)} \times 100 \%$, where $n(\infty)$ is the final value of the speed.

Adjustment times $(Z)$ : The number of times that the speed response value is equal to $n(\infty)$ in the adjusting process.

\subsection{Experimental Results under Healthy Condition}

Under healthy conditions, $k_{1}$ and $k_{2}$ are calculated as follow:

$$
k_{1}=\cos \frac{2 \theta_{0}+\omega(2 n-1) T-\omega(2 n-1) T}{2}\left(\frac{1}{T} \operatorname{arctg} \frac{U_{\mathrm{dc}} \times T}{\sqrt{3} \psi_{\mathrm{s}}}-\omega_{r}\right)
$$

where $\theta_{0}$ is the torque angle at $t_{0}, \omega$ is the angular frequency of stator flux linkage vector when the forward vectors are applied to the machine, $T$ is the sampling period, $\omega_{r}$ is the rotor angular frequency, $U_{d c}$ is the DC link voltage of the converter. 
The slope of the curve $\sin \theta$ from $t_{2}$ to $t_{3}$ can be expressed as:

$$
\begin{aligned}
& k_{2}=\frac{\sin \left(\theta_{2}-\omega_{r} n T\right)-\sin \left[\theta_{2}-\omega_{r}(n-1) T\right]}{T} \\
& =\frac{2}{T} \cos \frac{2 \theta_{2}-\omega_{\mathrm{r}}(2 n-1) T}{2} \sin \frac{-\omega_{r} T}{2} \\
& \approx \frac{1}{T} \cos \frac{2 \theta_{2}-\omega_{\mathrm{r}}(2 n-1) T}{2} \sin \left(-\omega_{r} T\right) \\
& \approx\left(-\omega_{r}\right) \cos \frac{2 \theta_{2}-\omega_{\mathrm{r}}(2 n-1) T}{2}
\end{aligned}
$$

where $\theta_{2}$ is the torque angle at $t_{2}$.

The experimental results under healthy conditions are as follows:

The experimental results of the DTC under $P=20$ and $I=0.8$ are given in Figure 22. Figure 23 shows the experimental results of the DTC under $P=10$ and $I=1.2$. In Figure 22, the speed exhibits several adjustment processes and the convergence time is $375 \mathrm{~ms}$. In Figure 23, the speed exhibits an obvious overshoot and the convergence time is $200 \mathrm{~ms}$.

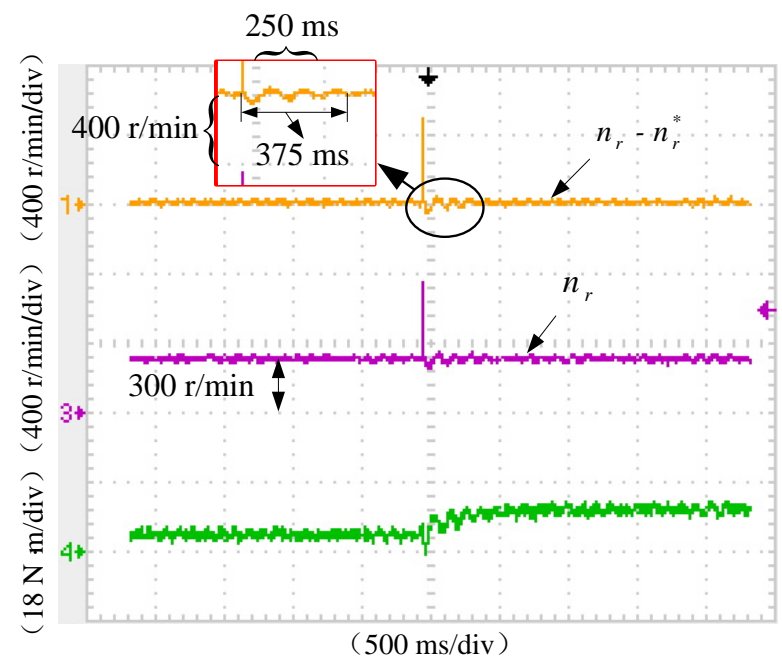

Figure 22. Experimental results of DTC $(P=20, I=0.8)$.

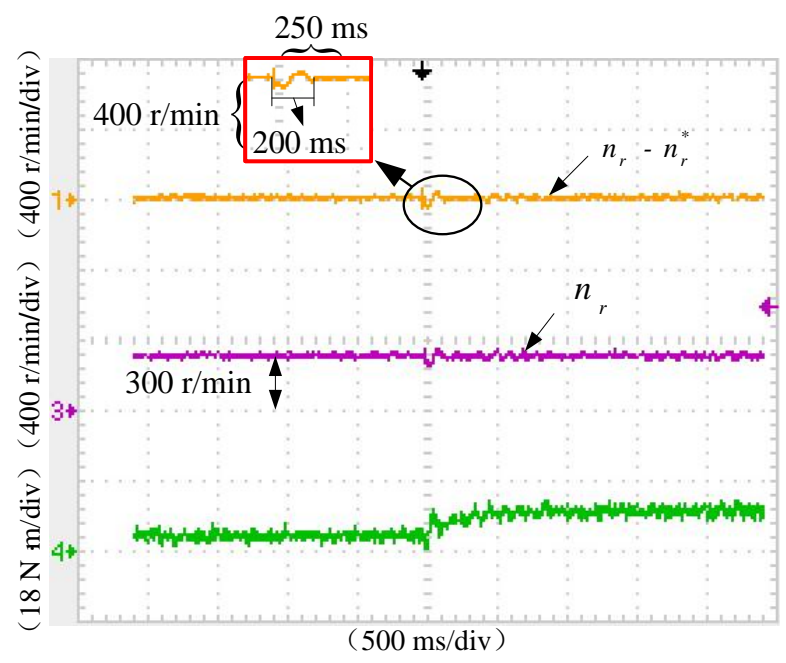

Figure 23. Experimental results of DTC $(P=10, I=1.2)$.

In Figure 24, when the load changes, recovery time of the speed is only $50 \mathrm{~ms}$ by using TIBC-DTC, meanwhile, the speed undershoot is $40 \mathrm{r} / \mathrm{min}$ and there is no overshoot. 


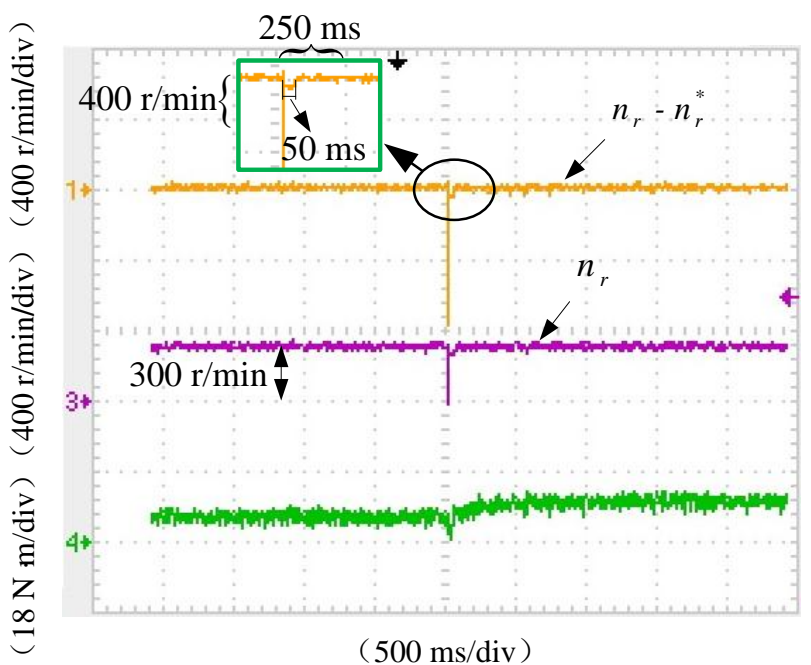

Figure 24. Experimental results of TIBC-DTC.

For better visualization, the experimental results of $n_{r}$ under DTC and TIBC-DTC are shown in Figure 25, and the performance metrics of DTC and TIBC-DTC are given in Table 5.

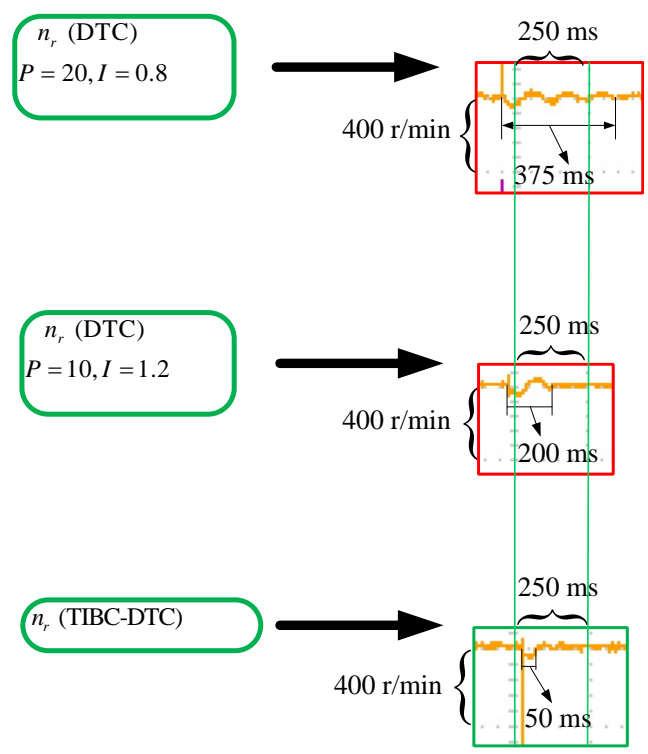

Figure 25. Experimental results of $n_{r}$ under DTC and TIBC-DTC.

Table 5. Performance metrics of DTC and TIBC-DTC (Experimental results).

\begin{tabular}{cccccc}
\hline Methods & $\boldsymbol{t}_{\mathrm{s}}$ & $\boldsymbol{t}_{\boldsymbol{p}}$ & $\Delta \boldsymbol{n}$-down & $\boldsymbol{\sigma} \%$ & $\boldsymbol{Z}$ \\
\hline DTC $(P=20, I=0.8)$ & $375 \mathrm{~ms}$ & $175 \mathrm{~ms}$ & $65 \mathrm{r} / \mathrm{min}$ & $21.67 \%$ & 6 \\
DTC $(P=10, I=1.2)$ & $200 \mathrm{~ms}$ & $160 \mathrm{~ms}$ & $48 \mathrm{r} / \mathrm{min}$ & $16.00 \%$ & 2 \\
TIBC-DTC & $50 \mathrm{~ms}$ & $50 \mathrm{~ms}$ & $40 \mathrm{r} / \mathrm{min}$ & $13.33 \%$ & 1
\end{tabular}

It can be concluded that the new method can minimize the speed overshoot and can achieve the shortest possible recovery time in load transient states, which agrees with previous theoretical analysis.

Figure 26 shows experimental results of TIBC-DTC under load step change $(5.5-11.5 \mathrm{~N} \cdot \mathrm{m})$. When the load changes, recovery time of the speed is only $55 \mathrm{~ms}$ by using TIBC-DTC; the speed undershoot is $75 \mathrm{r} / \mathrm{min}$ and there is no overshoot, which agrees with the theoretical analysis. It can be found that TIBC-DTC is still effective at different load changes. 


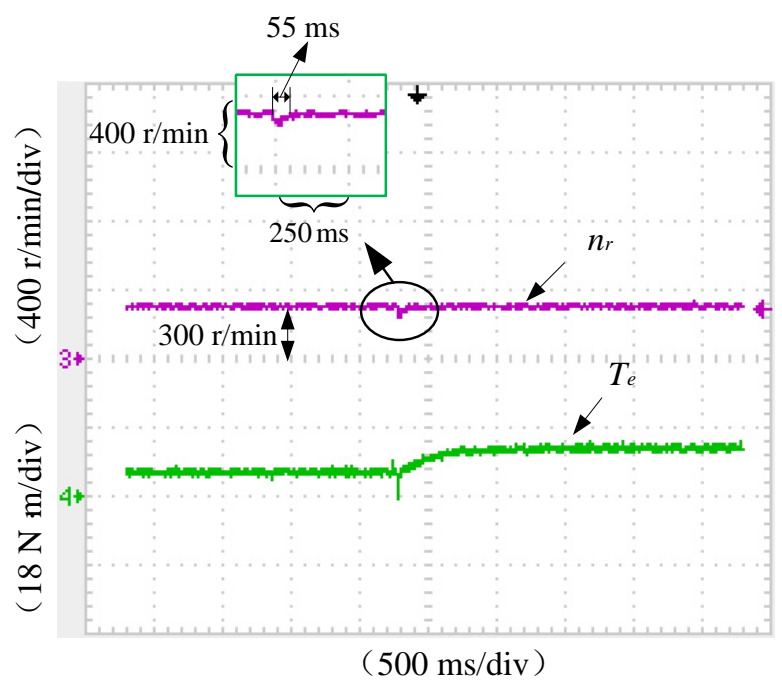

Figure 26. Experimental results of TIBC-DTC under load step change $(5.5-11.5 \mathrm{~N} \cdot \mathrm{m})$.

\section{Conclusions}

This paper investigates a torque impulse balance control for multi-tooth fault tolerant switched-flux machines under open-circuit fault. The following conclusions are obtained:

- Compared with the vector control with current vector compensation technology, the direct torque control with voltage vector reconstruction technique (RDTC) can achieve the electromagnetic torque with good dynamic performance, but for the rotor speed, its dynamic performance is always influenced by the PI parameters of the speed loop.

- In the dynamic process, the torque impulse balance control (TIBC) can obtain an optimal voltage vector sequence which has only one switch between forward vectors and zero vectors.

- The optimal voltage vector can achieve excellent dynamic performance of the rotor speed: (1) No overshoot in the speed; (2) Only one adjustment; (3) The shortest settling time.

Author Contributions: Y.W. is the main author of this paper who conceived the ideas and conducted the analysis. W.H. carried the experiments and simulations for this paper. All the authors have contributed significantly to this work.

Funding: This work was supported in part by the Chinese National Science Foundation under Project 51407090 and Project 51741705, the Power Electronics Science and Education Development of Delta Group under Project DREG2018014, and the Fundamental Research Funds for Central University under Project 1003-XAC18083 and Project 1003-XCA18154-04

Acknowledgments: We acknowledge the help of Liu Hui for the finite element analysis.

Conflicts of Interest: The authors declare no conflict of interest.

\section{References}

1. Chau, K.T.; Chan, C.C.; Liu, C.H. Overview of permanent-magnet brushless drives for electric and hybrid electric vehicles. IEEE Trans. Ind. Electron. 2008, 55, 2246-2257. [CrossRef]

2. Bianchi, N.; Bolognani, S.; Zigliotto, M. High-performance PM synchronous motor drive for an electrical scooter. IEEE Trans. Ind. Appl. 2001, 37, 1348-1355. [CrossRef]

3. Dúbravka, P.; Rafajdus, P.; Makyš, P.; Szabó, L. Control of Switched Reluctance Motor by Current Profiling under Normal and Open Phase Operating Condition. IET Electr. Power Appl. 2017, 11, 548-556. [CrossRef]

4. Miller, T.J.E. Electronic Control of Switched Reluctance Machines, 1st ed.; Newnes: Oxford, UK, 2001.

5. Pyrhönen, J.; Jokinen, T.; Hrabovcová, V. Design of Rotating Electrical Machines, 1st ed.; John Wiley \& Sons: Chichester, UK, 2008.

6. Jack, A.G.; Mecrow, B.C.; Haylock, J.A. A comparative study of permanent magnet and switched reluctance motors for high-performance fault-tolerant applications. IEEE Trans. Ind. Appl. 1996, 32, 889-895. [CrossRef] 
7. Ishak, D.; Zhu, Z.Q.; Howe, D. Comparison of PM brushless motors, with either all teeth or alternate teeth wound. IEEE Trans. Energy Convers. 2006, 21, 95-103. [CrossRef]

8. Ishak, D.; Zhu, Z.Q.; Howe, D. Permanent magnet brushless machines with unequal tooth widths and similar slot and pole numbers. IEEE Trans. Ind. Appl. 2005, 41, 584-590. [CrossRef]

9. Owen, R.L.; Zhu, Z.Q.; Thomas, A.S.; Jewell, G.W.; Howe, D. Fault-tolerant flux-switching permanent magnet brushless ac machines. In Proceedings of the IEEE Industry Applications Society Annual Meeting, Edmonton, AB, Canada, 5-9 October 2008; pp. 1-8.

10. Mecrow, B.C.; Jack, A.G.; Haylock, J.A.; Coles, J. Fault-tolerant permanent magnet machine drives. IEE Proc. Inst. Electr. Power Appl. 1996, 143, 437-442. [CrossRef]

11. Hua, H.; Zhu, Z.Q. Novel partitioned stator hybrid excited switched flux machines. IEEE Trans. Energy Convers. 2017, 32, 495-504. [CrossRef]

12. Wang, Y.; Deng, Z. A multi-tooth fault-tolerant flux-switching permanent-magnet machine with twisted-rotor. IEEE Trans. Magn. 2012, 48, 2674-2684. [CrossRef]

13. Owen, R.L.; Zhu, Z.Q.; Thomas, A.S.; Jewell, G.W.; Howe, D. Alternate poles wound flux-switching permanent-magnet brushless AC machines. IEEE Trans. Ind. Appl. 2010, 46, 790-797. [CrossRef]

14. Chen, J.T.; Zhu, Z.Q.; Howe, D. Stator and Rotor Pole Combinations for multi-tooth flux-switching PM brushless AC machines. IEEE Trans. Magn. 2008, 44, 4659-4667. [CrossRef]

15. Zhu, Z.Q.; Chen, J.T.; Pang, Y.; Howe, D.; Iwasaki, S.; Deodhar, R. Analysis of a novel multi-tooth flux-switching PM brushless AC machine for high torque direct-drive applications. IEEE Trans. Magn. 2008, 44, 4313-4316. [CrossRef]

16. Aboelhassan, M.O.; Raminosoa, T.; Goodman, A.; De Lillo, L.; Gerada, C. Performance evaluation of a vector-control fault-tolerant flux-switching motor drive. IEEE Trans. Ind. Electron. 2013, 60, 2997-3006. [CrossRef]

17. Hoang, K.D.; Zhu, Z.Q.; Foster, M. Direct torque control of permanent magnet brushless AC drive with single-phase open-circuit fault accounting for influence of inverter voltage drop. IET Electr. Power Appl. 2013, 7, 369-380. [CrossRef]

18. Gobbi, R.; Ramar, K. Optimisation techniques for a hysteresis current controller to minimise torque ripple in switch ed reluctance motors. IET Electr. Power Appl. 2009, 3, 453-460. [CrossRef]

19. Dubravka, P.; Rafajdus, P.; Makys, P.; Peniak, A.; Hrabovcova, V.; Szabo, L.; Ruba, M. Design of fault tolerant control technique for SRM drive. In Proceedings of the 2014 16th European Conference on Power Electronics and Applications (EPE'4-ECCE Europe), Lappeenranta, Finland, 26-28 August 2014; pp. 1-8.

20. Gameiro, N.S.; Cardoso, A.J.M. Fault tolerant cont rol strategy of SRM drives. In Proceedings of the International Symposiun on Power Electronics, Electrical Drives, Automation and Motion, Ischia, Italy, 11-13 June 2008; pp. 301-306.

21. Mir, S.; Islam, M.S.; Sebastian, T.; Husain, I. Fault-tolerant switched reluctance motor drive using adaptive fuzzy logic controller. IEEE Trans. Power Electron. 2004, 19, 289-295. [CrossRef]

22. Zeng, H.; Chen, H.; Shi, J. Direct instantaneous torque control with wide operating range for switched reluctance motors. IET Electr. Power Appl. 2015, 9, 578-585. [CrossRef]

23. Cheng, H.; Chen, H.; Yang, Z. Average torque control of switched reluctance machine drives for electric vehicles. IET Electr. Power Appl. 2015, 9, 459-468. [CrossRef]

24. Sahin, C.; Amac, A.E.; Karacor, M.; Emadi, A. Reducing torque ripple of switched reluctance machines by relocation of rotor moulding clinches. IET Electr. Power Appl. 2012, 6, 753-760. [CrossRef]

25. Inderka, R.B.; De Doncker, R.W.A.A. DITC-direct instantaneous torque control of switched reluctance drives. IEEE Trans. Ind. Appl. 2003, 39, 1046-1051. [CrossRef]

26. Wong, K.F.; Cheng, K.W.E.; Ho, S.L. Four-quadrant instantaneous torque control of switched reluctance machine at low speed based on co-energy control. IET Electr. Power Appl. 2009, 3, 431-444. [CrossRef]

27. Vujicic, V.P. Mini mization of torq ue ripple and copper losses in switched reluctance drive. IEEE Trans. Power Electron. 2012, 27, 388-399. [CrossRef]

28. Schramm, D.S.; Williams, B.W.; Green, T.C. Torque ripple reduction of switched reluctance motors by phase current optimal profiling. In Proceedings of the Power Electronics Specialists Conference, Toledo, Spain, 29 June-3 July 1992; pp. 857-860. 
29. Venkatesha, L.; Ramanarayanan, V. Torque ripple minimisation in switched reluctance motor with optimal control of phase currents. In Proceedings of the International Conference on Power Electronics, Drives and Energy Systems for Industrial Growth, Perth, Australia, 1-3 December 1998; pp. 529-534.

30. Shaked, N.T.; Rabinovici, R. New procedures for minimizing the torque ripple in switched reluctance motors by optimizing the phase- current profile. IEEE Trans. Magn. 2005, 41, 1184-1192. [CrossRef]

31. Mikail, R.; Sozer, Y.; Husain, I.; Islam, M.S.; Sebastian, T. Torque ripple minimization of switched reluctance machines through current pro filing. IEEE Trans. Ind. Appl. 2013, 49, 1258-1267. [CrossRef]

32. Zhao, W.; Cheng, M.; Chau, K.T.; Hua, W.; Jia, H.; Ji, J.; Li, W. Stator-flux-oriented fault-tolerant control of flux-switching permanent-magnet motors. IEEE Trans. Magn. 2011, 47, 4191-4194. [CrossRef]

33. Zhao, W.; Cheng, M.; Hua, W.; Jia, H.; Cao, R. Back-EMF Harmonic Analysis and Fault-Tolerant Control of Flux-Switching Permanent-Magnet Machine with Redundancy. IEEE Trans. Ind. Electron. 2011, 58, 1926-1935. [CrossRef]

34. Zhao, W.; Cheng, M.; Chau, K.T.; Cao, R.; Ji, J. Remedial Injected-Harmonic-Current Operation of Redundant Flux-Switching Permanent-Magnet Motor Drives. IEEE Trans. Ind. Electron. 2013, 60, 151-159. [CrossRef]

35. Buja, G.S.; Kazmierkowski, M.P. Direct torque control of PWM inverter-fed AC motors-A survey. IEEE Trans. Ind. Electron. 2004, 51, 744-757. [CrossRef]

36. Ren, Y.; Zhu, Z.Q. Enhancement of steady-state performance in direct-torque-controlled dual three-phase permanent-magnet synchronous machine drives with modified switching table. IEEE Trans. Ind. Electron. 2015, 62, 3338-3350. [CrossRef]

37. Hu, Y.; Zhang, L.; Huang, W.; Bu, F. A fault-tolerant induction generator system based on instantaneous torque control (ITC). IEEE Trans. Energy Convers. 2010, 25, 412-421. [CrossRef]

38. Jia, L.; Liu, Y.F. Voltage-Based Charge Balance Controller Suitable for Both Digital and Analog Implementations. IEEE Trans. Power Electron. 2013, 28, 930-944. [CrossRef]

(C) 2018 by the authors. Licensee MDPI, Basel, Switzerland. This article is an open access article distributed under the terms and conditions of the Creative Commons Attribution (CC BY) license (http:/ / creativecommons.org/licenses/by/4.0/). 